\title{
Инна Вершинина
}

\section{Anna R. Davies. Urban Food Sharing: Rules, Tools and Networks. Bristol, UK: Policy Press, 2019. 104 pp. ISBN 978-1-4473-4982-2.}

\author{
Инна Вершинина, кафедра современной социологии, социологический фа- \\ культет МГУ имени М. В. Ломоносова. Адрес для переписки: Социологиче- \\ ский факультет МГУ, Ленинские горы, д. 1, стр. 33, Москва, 119234, Россия. \\ urbansociology@yandex.ru.
}

Книга Анны Дэвис, профессора Тринити-колледжа в Дублине, «Фудшеринг в городе: правила, механизмы и сети» затрагивает интересные аспекты формирующейся шеринговой культуры, касающиеся продовольственных цепочек. Эта работа является одним из результатов довольно масштабного проекта Sharecity, стартовавшего в 2016 году. Его участники полагают, что многие современные города далеки от идеалов устойчивого развития в том числе и в сферах потребления продуктов питания, а также утилизации пищевых отходов. С их точки зрения, совместное использование, или шеринг, может стать одним из преобразующих механизмов, ведущих к созданию устойчивых городов ${ }^{1}$. По словам Дэвис, ее цель заключается в том, чтобы начать заполнять пробел в нашем понимании фудшеринга и изучении его возможностей, способствующих созданию устойчивых продовольственных систем (с. 4). Основой исследования стали современные практики фудшеринга в 100 городах мира, особое внимание уделяется тем практикам, которые опосредованы информационно-коммуникационными технологиями (ИКТ). Подробную информацию о них можно найти в базе данных проекта Sharecity, где практики фудшеринга систематизированы не только по городам, но и по объектам, которые совместно используются, формам организации и наличию/отсутствию вознаграждения для участников (Davies et al. 2016).

Книгу Дэвис можно рассматривать как продолжение написанной годом ранее в соавторстве с Дэвидом Эвансом статьи «Urban Foodsharing: Emerging Geographies of Production, Consumption and Exchange», в которой указывается на то, что современные города стали полем постоянных экспериментов и инноваций, в том числе и в сфере производства, обмена и совместного потребления пищевых продуктов (Davies and Evans 2018). Авторы рассматривают различные коллективные и совместные практики в области питания, начиная с выращивания, приготовления еды и ее употребления и заканчивая перераспределением излишков, а также использованием общих пространств и устройств для производства, приготовления и потребления пищи.

Города оказываются в центре внимания авторов не только по той причине, что их жители составляют более половины населения мира, но и потому, что они являются главными центрами потребления ресурсов и, соответственно, производства отходов, из которых от 47 до 61\% - органические, преимущественно пищевые

1 https://sharecity.ie. 
отходы, причем прогнозируется, что производство пищевых отходов увеличится вдвое в течение последующих 15 лет (Davies and Evans 2018). Несмотря на то, что в мире по-прежнему голодают сотни миллионов людей, значительные ресурсы растрачиваются для производства, хранения и распределения пищи, которая утилизируется. Поэтому необходимо понять, каким образом можно оптимизировать продовольственные цепочки, чтобы способствовать более сбалансированному потреблению, отвечающему принципам устойчивого развития.

Эта проблема представляет значительный интерес и для России, где утилизация отходов уже стала причиной ряда социальных конфликтов, а новшества в данной сфере внедряются с большими сложностями. Более того, фудшеринговые сообщества в России позиционируют себя в первую очередь как экологические инициативы (например, «Движение фудшеринг»²), чья цель состоит прежде всего в минимизации количества выбрасываемых пищевых продуктов. Соответственно, фудшеринг по-российски - это прежде всего эффективное управление излишками продуктов питания, о необходимости чего пишут и зарубежные авторы (Richards and Hamilton 2018).

Тем самым фудшеринг в нашей стране, как правило, понимается более узко, чем предлагают Дэвис и Эванс. Для них фудшеринг - это совместное приготовление и употребление еды, предоставление другим ее части, наличие совместных площадей для выращивания и приготовления пищи, использование общей посуды и садовых инструментов, общее увлечение едой, а также рассказы о своих кулинарных навыках и знаниях о еде (Davies and Evans 2018). Причем речь идет как о безвозмездном совместном использовании, на котором основана примерно треть инициатив (с. 36), так и об обмене и даже услугах, предполагающих выплату вознаграждения. Совместное использование может быть мотивировано целым рядом факторов - альтруизмом, желанием оптимизировать свои расходы и многими другими, но для Дэвис наиболее значимым является стремление стимулировать создание более устойчивых городских продовольственных систем, способствующих решению экономических, социальных и экологических проблем (с. 70).

В рецензируемой книге 2019 года автор продолжает придерживаться подхода, разработанного совместно с коллегами, на исследования которых она постоянно ссылается. Книга состоит из шести частей: первая - введение, в котором обосновывается значимость фудшеринга; вторая часть описывает специфику фудшеринговых практик в городском пространстве; третья предполагает выявление сформировавшихся правил и норм; в четвертой анализируются технологии фудшеринга, основой для которых являются ИКТ; в пятой рассматриваются сети, ставшие следствием устойчивых интеракций и коммуникаций; шестая - заключение, где описываются существующие тенденции и перспективы дальнейшего развития изучаемых социальных практик.

Исследовательской базой стали более 4000 инициатив по фудшерингу в 100 городах на территории 43 стран, расположенных на шести континентах. Необходимо отметить, что около трети инициатив реализуется всего в 10 городах из 100 -

2 https://foodsharing.ru. 
Лондоне, Нью-Йорке, Мельбурне, Берлине, Сиднее, Барселоне, Филадельфии, Чикаго, Буэнос-Айресе и Ванкувере (с. 22). Из рассмотренных инициатив 13 приходится на один из российских городов - Москву, занявшую 88 место в общем рейтинге. Подробнее со всеми инициативами можно ознакомиться в открытой базе данных, созданной в 2016 году (Davies et al. 2016). У регионов есть свои особенности, но если характеризовать общую картину, то можно отметить, что чаще всего люди делятся своими знаниями и навыками (53\%), готовыми блюдами $(35 \%)$, фруктами и овощами (33\%), а реже всего мясом и рыбой (4\%). Причем в 26\% случаев предполагается совместное употребление пищи.

Различия в практиках фудшеринга каждой из стран детерминированы не только культурой, но и нормативно-правовой базой, которая зачастую создает барьеры для некоторых инициатив, поскольку законодательство может довольно жестко регламентировать все, что касается оборота пищевых продуктов даже на некоммерческой основе. Если практики фудшеринга оказываются незаконными в соответствии с существующими нормативными актами, то эти инициативы имеют мало возможностей для продолжения, поскольку заинтересованные в них субъекты имеют недостаточно власти и влияния для пересмотра законодательства (с. 46-47). Таким образом, иногда оказывается проще утилизировать продукты, чем раздать их тем, кто в этом нуждается. Тем самым социально-экономические проблемы усугубляются (Sbicca 2018), хотя есть субъекты, готовые способствовать их решению в случае изменения нормативно-правовой базы.

Дэвис отмечает, что фудшеринг - инициатива, не только способствующая устойчивому потреблению, но и имеющая явные социально-психологические эффекты. Совместное употребление пищи постепенно уходит в прошлое в некоторых странах (например, каждый пятый прием пищи в США происходит в автомобиле), хотя имеет большое значение для психологического состояния людей, формирования и поддержания их идентичности, включенности в социальные группы, профилактики девиантного поведения у детей и подростков и т. д. (с. 2). Фудшеринг также может способствовать улучшению социально-психологического состояния людей, поскольку в рамках ряда инициатив существует множество разнообразных возможностей для приобретения или развития новых навыков, связанных с выращиванием, приготовлением еды, приемом пищи и ее перераспределением (с. 76). Эти новые навыки приобретаются или передаются в результате включенности в социальные взаимодействия, что довольно важно для современного мира, где множество домохозяйств состоят из одного человека. Более того, исследования свидетельствуют о том, что инициативы с высокой степенью социальной активности с большей вероятностью станут основой для новых социальных отношений (политических, экологических, экономических и других). Тем самым инициативы по фудшерингу создают благоприятные условия не только для объединения людей, но и для перемен в их жизни и в обществе в целом (с. 83).

Очевидно, что важным фактором роста популярности фудшеринга стало появление мобильных цифровых технологий, которые на протяжении всего XX столетия становились все более доступными и простыми в использовании (с. 21). Неудивительно, что основная масса инициатив возникла относительно недавно - 
после 2008 года, когда экономический кризис обострил ряд социальных проблем, для решения которых были найдены новые подходы, включающие в себя и фудшеринг. Дэвис рассматривает интернет-сайты, социальные сети (в первую очередь Facebook, Twitter и Meetup) и мобильные приложения, поскольку они предлагают онлайн-пространства, где потенциальные участники могут контактировать друг с другом (с. 50). В значительной степени именно ИКТ, став привычной составляющей городской жизни во многих странах, обеспечили пространственную и временную связанность, позволившую сильно расширить возможности взаимодействия в сферах производства и потребления.

Дэвис в своей работе демонстрирует, что современный фудшеринг имеет место в городах по всему миру - малых и больших, бедных и богатых, на севере и на юге, - что позволяет говорить о фудшеринге как о международном явлении, характерном не только для «умных городов», хотя ИКТ играют существенную роль в его распространении. Подводя итоги, она выделяет следующие тенденции развития фудшеринга в современных городах: во-первых, экспоненциальный рост числа инициатив с 2008 года; во-вторых, успешность большинства инициатив благодаря многофункциональности многих из них и выбору стратегий, способствующих устойчивому развитию продовольственных систем; в-третьих, популяризация инициатив вследствие демонстрации их потенциала в решении социальных, экологических и экономических проблем, среди которых все большее значение (в том числе и политическое) приобретает необходимость утилизации пищевых отходов; в-четвертых, частое отсутствие целенаправленной продовольственной стратегии на уровне городских органов власти, что делает многие инициативы инновационными и востребованными (с. 88-92). Перспективы развития фудшеринга очевидны, особенно учитывая тот факт, что глобальная продовольственная система не в состоянии удовлетворить потребности всех жителей планеты, a ее возможности в будущем могут быть еще больше ограничены вследствие изменений климата. Создание устойчивых городских продовольственных систем в условиях изменений климата и растущей урбанизации превращается в «метасоциальную проблему» (с. 98), которая требует поиска новых решений.

\section{СПИСОК ЛИТЕРАТУРЫ}

Davies, Anna R., Ferne Edwards, Brigida Marovelli, Oona Morrow, Monika Rut, and Marion Weymes. 2016. SHARECITY100 Database, Trinity College Dublin, Ireland. http://sharecity.ie/research /sharecity100-database.

Davies, Anna R., and David Evans. 2018. “Urban Food Sharing: Emerging Geographies of Production, Consumption and Exchange." Geoforum 99:154-159. doi:10.1016/J.geoforum.2018.11.015.

Richards, Timothy J., and Stephen F. Hamilton. 2018. "Food Waste in the Sharing Economy." Food Policy 75:109-123. doi:10.1016/j.foodpol.2018.01.008.

Sbicca, Joshua. 2018. Food Justice Now! Deepening the Roots of Social Struggle. Minneapolis: University of Minnesota Press. 